\title{
Influences of surface-coated fulvic and humic acids on the adsorption of metal cations to $\mathrm{SiO}_{2}$ nanoparticles
}

\author{
Liang Liang ${ }^{\mathrm{a}}$, Jitao $\mathrm{Lv}^{\mathrm{a}}$, Lei Luo ${ }^{\mathrm{a}}$, Jing Zhang ${ }^{\mathrm{b}}$, Shuzhen Zhanga,* \\ a State Key Laboratory of Environmental Chemistry and Ecotoxicology, Research Center for Eco-Environmental Sciences, the Chinese Academy of Sciences, Beijing 100085, China \\ b State Key Laboratory of Synchrotron Radiation, Institute of High Energy Physics, Chinese Academy of Sciences, Beijing 100039, China
}

\section{A R T I C L E I N F O}

\section{Article history:}

Received 20 July 2011

Received in revised form 31 August 2011

Accepted 1 September 2011

Available online 8 September 2011

\section{Keywords:}

Adsorption

$\mathrm{SiO}_{2}$

Fulvic acid

Humic acid

Metal cations

X-ray absorption spectroscopy

\begin{abstract}
A B S T R A C T
Humic substances such as fulvic acid (FA) and humic acid (HA) exist universally in the environment and play an important role in the interfacial reactions of contaminants. In this study, influences of surfacecoated $\mathrm{FA}$ and $\mathrm{HA}$ on the adsorption of metal cations of $\mathrm{Cu}(\mathrm{II}), \mathrm{Pb}(\mathrm{II})$ and $\mathrm{Zn}(\mathrm{II})$ on $\mathrm{SiO}_{2}$ nanoparticles (nano- $\mathrm{SiO}_{2}, 20 \mathrm{~nm}$ ) were investigated. The results showed that nano- $\mathrm{SiO}_{2}$ had high adsorption capacities for the metal cations following the sequence of $\mathrm{Pb}(\mathrm{II})>\mathrm{Cu}(\mathrm{II})>\mathrm{Zn}$ (II), irrespective of coating with FA or HA. Nano-SiO ${ }_{2}$ had a strong affinity for FA and $\mathrm{HA}$, and coating with FA and HA significantly enhanced the adsorption of the metal cations on nano- $\mathrm{SiO}_{2}$. Cation adsorption on the original and coated nano$\mathrm{SiO}_{2}$ followed the same pronounced increasing trend with increasing $\mathrm{pH}$. X-ray absorption spectroscopy (XAS) analysis by taking $\mathrm{Cu}(\mathrm{II})$ as an example revealed that $\mathrm{Cu}(\mathrm{II})$ was adsorbed on nano-SiO ${ }_{2}$ by forming inner-sphere complexes; whereas its adsorption on $\mathrm{FA} / \mathrm{HA}$ coated nano-SiO ${ }_{2}$ was through complexing with the hydroxyl moieties and organic functional groups of FA/HA as bridges. This work demonstrates that FA and HA can significantly change the adsorption capacities and mechanisms for metal cations and thus likely influence their behaviors in the environment.
\end{abstract}

(C) 2011 Elsevier B.V. All rights reserved.

\section{Introduction}

Nanoparticles, as a new group of materials, have been receiving increasing attention worldwide over the last decade. The production, use, and disposal of nanoparticles will inevitably lead to their release into the environment [1], exerting potentially harmful effects on ecological and human health [2]. Owing to their extremely small size, nanoparticles have a much greater surface area and abundant surface reactive sites, which make them highly reactive to contaminants such as heavy metals and thereby inevitably change behaviors of the contaminants in the environment [3]. Among various nanoparticles, nano-oxides, particularly nano silicon dioxide (nano- $\mathrm{SiO}_{2}$ ), have been the most widely used and thus received much attention [4]. It has been demonstrated that nano-oxides have a higher adsorption affinity for heavy metals such as $\mathrm{Pb}, \mathrm{Cu}, \mathrm{Zn}$ and $\mathrm{Cd}$ compared with particles of bulk size $[5,6]$. However, the real behaviors of nano-oxides and particularly their interfacial reaction mechanisms in the environment are still less well understood.

Humic substances (HS) exist universally in the aquatic and soil environments and they carry a large number of functional groups

\footnotetext{
* Corresponding author. Tel.: +8610 62849683; fax: +86 1062923563.

E-mail address: szzhang@rcees.ac.cn (S. Zhang).
}

(e.g., carboxylate, phenolate, amino and thiol). Previous studies have shown that the adsorption of HS can significantly modify the oxide surface characteristics [7]. In addition, adsorption of HS will definitely introduce some functional groups of HS to oxide surfaces [8]. These modifications strongly affect the adsorption of metal cations on the oxides [9-11]. The most recent researches have shown that nano-oxides have a strong affinity for HS such as fulvic acid (FA) and humic acid (HA) [12,13]. Therefore, it can be expected that once released into the environment, nano-oxides may be coated by HS over time, which will modify the characteristics of nano-oxides and inevitably influence the sorption behaviors of heavy metals on them. Nevertheless, how HS influence the adsorption of metal cations on nano-oxides is still unknown.

In a previous work we have investigated the interaction of nano- $\mathrm{SiO}_{2}$ with $\mathrm{FA}$ and $\mathrm{HA} \mathrm{[13].} \mathrm{In} \mathrm{the} \mathrm{present} \mathrm{study} \mathrm{we} \mathrm{extended}$ this work to explore the influence of FA/HA on the interaction of heavy metals with nano-oxides by examining and comparing the adsorption of metal cations $\mathrm{Cu}$ (II), $\mathrm{Pb}$ (II) and $\mathrm{Zn}$ (II) on nano$\mathrm{SiO}_{2}$ and FA- and HA-coated nano-SiO 2 . Factors including $\mathrm{pH}$ and ionic strength that were assumed to influence the adsorption were investigated. X-ray absorption spectroscopy (XAS) can provide a powerful tool to characterize the coordination environment of metal cations. Therefore, XAS including X-ray absorption near-edge structure (XANES) and extended X-ray absorption fine-structure (EXAFS) spectroscopy was employed to interpret the coordination 
characteristics of metal cations adsorbed on nano- $\mathrm{SiO}_{2}$. This study will be helpful to understand the important role of HS on sorption of metal cations onto nano-oxides.

\section{Materials and methods}

\subsection{Preparation and characterization of FA- and HA-coated nano- $\mathrm{SiO}_{2}$}

$\mathrm{SiO}_{2}$ particles in size of $20 \mathrm{~nm}$ were obtained from Alfa Aesar, Johnson Matthey Company. FA and HA were extracted from a forest soil from the suburbs of Beijing following the International Humic Substances Society procedures [14]. The purified FA and HA materials contained $47 \%$ and $59 \%$ of carbon, respectively. Functional compositions of FA and $\mathrm{HA}$ and their distribution on $\mathrm{SiO}_{2}$ nanoparticles were examined with Fourier Transform Infrared (FTIR) spectroscopy as described previously [13]. All the chemicals used were of analytical grade or better.

FA and HA coated $\mathrm{SiO}_{2}$ nanoparticles $\left(\mathrm{SiO}_{2}-\mathrm{FA}\right.$ and $\mathrm{SiO}_{2}-\mathrm{HA}$, respectively) were prepared from $0.5 \mathrm{~g} / \mathrm{L} \mathrm{SiO}_{2}$ suspensions in the presence of $700 \mathrm{mg} / \mathrm{L}$ FA or HA. The $\mathrm{pH}$ was adjusted to and maintained at 4.0 in an ionic strength of $0.01 \mathrm{~mol} / \mathrm{L} \mathrm{NaNO}_{3}$ plus $0.1 \mathrm{~g} / \mathrm{L}$ $\mathrm{NaN}_{3}$. The suspensions were continuously shaken for $72 \mathrm{~h}$. To check the stability of FA/HA coating, desorption experiment was performed three times sequentially by replacing half of the adsorption equilibrium solution after centrifugation with the ionic strength and adjusting the $\mathrm{pH}$ to the original value.

To determine the influence of FA and HA coating on the characteristics of the nano- $\mathrm{SiO}_{2}$, the original and the treated nanoparticles were characterized in terms of their $\mathrm{N}_{2}$ surface area $\left(\mathrm{N}_{2} \mathrm{SA}\right)$, particle size, $\zeta$ potentials and isoelectric point (IEP). The particle size was determined by Laser Particle Size Analyzer (Mastersizer 2000, Marlven, Ltd. UK) and the average diameter values were 60 and $75 \mathrm{~nm}$ for $\mathrm{SiO}_{2}-\mathrm{FA}$ and $\mathrm{SiO}_{2}-\mathrm{HA}$ particles, respectively.

\subsection{Adsorption of metal cations}

Adsorption kinetics and isotherms were determined by a batch technique in a background electrolyte of $0.01 \mathrm{~mol} / \mathrm{L} \mathrm{NaNO}_{3}$ plus $0.1 \mathrm{~g} / \mathrm{L} \mathrm{NaN}_{3}$. Experiments were conducted in $50 \mathrm{~mL}$ polyethylene centrifuge tube containing $0.5 \mathrm{~g} / \mathrm{L}$ adsorbent, and $\mathrm{pH}$ of the system was maintained at 5.0. For adsorption kinetics, the initial concentration of each metal cation was $1.0 \mathrm{mmol} / \mathrm{L}$. The suspensions were continuously shaken for up to $210 \mathrm{~min}$ and collected at different time intervals from 2 to $30 \mathrm{~min}$. For adsorption isotherms, the initial concentrations of each metal cation ranged from 0.2 to $2.5 \mathrm{mmol} / \mathrm{L}$, and the suspensions were shaken for $180 \mathrm{~min}$ based on the results of kinetic experiments. After the samples were shaken end-over-end in the dark at room temperature for a given time, the suspensions were centrifuged at $7200 \times g$ for $15 \mathrm{~min}$, filtered through a $0.45 \mu \mathrm{m}$ cellulose nitrate membrane, acidified and then the metal concentrations were determined by inductively coupled plasma-mass spectrometer (ICP-MS, 7500c, Agilent Technologies Inc., USA). The amount of metal adsorbed was deduced from the mass balance between the initial concentration and the concentration in solution at a given time. The preliminary experiment has indicated that the adsorption of metal cations on the membrane was less than $1 \%$ of the adsorbates added and therefore can be neglected.

\subsection{Effects of $\mathrm{pH}$ and ionic strength on metal cation adsorption}

Two hundred milligram of each adsorbent was introduced into a reaction vessel with $400 \mathrm{~mL}$ background electrolyte inside. The suspension was then added with metal stock solution to achieve the concentration of $0.2 \mathrm{mmol} / \mathrm{L}$ for each metal cation. The suspension was stirred and titrated to a higher $\mathrm{pH}$ by stepwise addition of dilute $\mathrm{HNO}_{3}$ or $\mathrm{NaOH}$. After each $\mathrm{pH}$ increment was reached, a $20 \mathrm{~mL}$ aliquot was transferred from the reaction vessel to a $40 \mathrm{~mL}$ centrifuge tube and shaken in the dark at room temperature for $180 \mathrm{~min}$. The final $\mathrm{pH}$ was measured and the suspensions were centrifuged, acidified, and analyzed for metal cation concentrations. To examine the effect of ionic strength, adsorption of metal cations on each adsorbent was performed in background electrolytes of 0.01 and $0.1 \mathrm{~mol} / \mathrm{L} \mathrm{NaNO}_{3}$, respectively.

\subsection{Adsorption models}

The adsorption kinetics of metal cations on each adsorbent was described with the pseudo-second-order kinetic model $[15,16]$ using the following equation:

$\frac{t}{q_{t}}=\frac{1}{k q_{e}^{2}}+\frac{t}{q_{e}}$

where $k$ is the rate constant for the pseudo-second-order model, $q_{e}$ and $q_{t}$ are the amounts of solute adsorbed per unit adsorbent at equilibrium and at time $t$, respectively. Herein, the initial adsorption rate $\left(v_{0}\right)$ is calculated as: $v_{0}=k q_{e}{ }^{2}$.

The adsorption isotherm data were fitted with the Langmuir model:

$q_{e}=\frac{K_{L} q_{\max } C_{e}}{1+K_{L} C_{e}}$

where $q_{e}(\mathrm{mmol} / \mathrm{g})$ is the adsorbed metal cation concentration at equilibrium, $q_{\max }$ is the predicted maximum adsorbed capacity, $K_{L}$ $(\mathrm{L} / \mathrm{mmol})$ is the Langmuir adsorption equilibrium constant related to the energy or net enthalpy, and $C_{e}(\mathrm{mmol} / \mathrm{L})$ is the equilibrium concentration of metal cation in solution.

\subsection{XAS data collection and analysis}

X-ray absorption spectroscopy data at Cu K-edge ( $8979 \mathrm{eV})$ were collected at the 1W1B beamline of the Beijing Synchrotron Radiation Facility (BSRF) using a Si(111) double crystal monochromator. The storage ring was operated at $2.2 \mathrm{GeV}$ with an average beam current of $80 \mathrm{~mA}$. To minimize the unwanted harmonics, the parallelism of the two crystals in the monochromator was adjusted to mistune the incident beam by $30 \%$. Wet samples obtained by decanting the supernatant after the adsorption experiments with the initial concentration of $2 \mathrm{mmol} / \mathrm{L}$ were loaded into Teflon ${ }^{\circledR}$ sample holders and sealed with Kapton tape. Spectra of the adsorption samples were collected in fluorescence mode with a Lytle-type fluorescence detector (EXAFS Company, Pioche, NV, USA) at room temperature. Reference compounds were collected in transmission mode. Spectra were acquired using a $0.6 \mathrm{eV}$ step size around the absorption edges and $3.0 \mathrm{eV}$ step size above and below the edges. Three scans were averaged for each of the standards and adsorption samples.

Data analysis was performed with WinXAS 3.0 with the procedure of background correction and normalization, cubic spline, Fourier transformation, reverse Fourier transformation and EXAFS fitting. In the fitting process, the coordination number was fixed for the reference compounds, while the Debye-Waller factor was fixed for samples. Phase shifts and backscattering amplitudes were obtained from the theoretical calculation using FEFF 7.0 [17].

\subsection{Quality assurance and data analysis}

All experiments were carried out in triplicate and blanks were run in parallel. The cation concentrations in water standard reference material (GBW 080080, purchased from Shanghai Institute 
Table 1

Pseudo-second-order kinetic parameters for metal ions adsorption on $\mathrm{SiO}_{2}$, $\mathrm{SiO}_{2}$-humic acid and $\mathrm{SiO}_{2}$-fulvic acid nanoparticles.

\begin{tabular}{|c|c|c|c|c|c|}
\hline Adsorbent & Cation & $v_{0}\left(\times 10^{-2} \mathrm{mmol} / \mathrm{g} / \mathrm{min}\right)$ & $k(\mathrm{~g} / \mathrm{mmol} / \mathrm{min})$ & $q_{e}(\mathrm{mmol} / \mathrm{g})$ & S.E. ${ }^{a}\left(\times 10^{-2}\right)$ \\
\hline \multirow[t]{3}{*}{$\mathrm{SiO}_{2}$} & $\mathrm{~Pb}$ & 6.153 & 0.413 & 0.386 & 1.097 \\
\hline & $\mathrm{Cu}$ & 5.941 & 0.562 & 0.325 & 1.013 \\
\hline & $\mathrm{Zn}$ & 3.056 & 0.952 & 0.179 & 0.478 \\
\hline \multirow[t]{3}{*}{$\mathrm{SiO}_{2}-\mathrm{HA}$} & $\mathrm{Pb}$ & 25.75 & 0.171 & 1.228 & 3.526 \\
\hline & $\mathrm{Cu}$ & 11.05 & 0.087 & 1.128 & 1.513 \\
\hline & $\mathrm{Zn}$ & 4.630 & 0.075 & 0.786 & 0.740 \\
\hline \multirow[t]{3}{*}{$\mathrm{SiO}_{2}-\mathrm{FA}$} & $\mathrm{Pb}$ & 13.24 & 0.143 & 0.962 & 1.999 \\
\hline & $\mathrm{Cu}$ & 10.16 & 0.138 & 0.859 & 1.271 \\
\hline & $\mathrm{Zn}$ & 4.553 & 0.166 & 0.524 & 0.569 \\
\hline
\end{tabular}

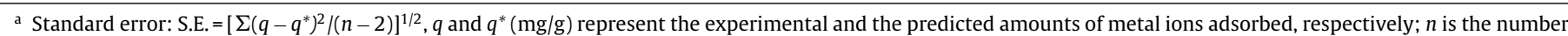
of experimental points.

of Measurement and Testing Technology, Shanghai, China) were determined for quality assurance of metal analysis. The data obtained and the certified values were in good agreement with the differences of less than $10 \%$. The adsorption models were fitted by Origin 7.5 software at the $95 \%$ confidence level, and evaluation of the deviation of the experimental data from the modeling curves was performed using the MS-Excel 2003.

\section{Results}

\subsection{Characterization of the adsorbents}

The coating experiments indicated that nano- $\mathrm{SiO}_{2}$ particles had a strong affinity for FA and HA. The adsorption capacities of FA and HA were 369 and $560 \mathrm{mg} / \mathrm{g}$, and only $9.3 \%$ and $7.5 \%$ of the adsorbed FA and HA were desorbed, respectively, after three sequential desorption steps. Nano-SiO 2 particles had a $\mathrm{N}_{2} \mathrm{SA}$ of $578 \mathrm{~m}^{2} / \mathrm{g}$, while the $\mathrm{N}_{2}$ SAs were significantly decreased to 317 and $386 \mathrm{~m}^{2} / \mathrm{g}$ after being coated with FA and HA, respectively. With the modification of surface functional groups by the coated FA and HA, the nanoparticles exhibited higher amounts of aromatic, carboxyl and carbonyl moieties on their surfaces as confirmed by the FTIR results [13].

\subsection{Cation adsorption characteristics}

Adsorption kinetics of the metal cations on $\mathrm{SiO}_{2}$ and $\mathrm{FA} / \mathrm{HA}$ coated $\mathrm{SiO}_{2}$ nanoparticles are shown in Fig. 1, together with the fittings of the pseudo-second-order kinetic model. The adsorption data can be satisfactorily described by the model $\left(R^{2} \geq 0.999\right)$ (Table 1 ), which was also confirmed by the standard errors between the experimental and the predicted data. The adsorption obviously entailed a very rapid process of about $30 \mathrm{~min}$ followed by a slow adsorption process. After $180 \mathrm{~min}$, a relative equilibrium

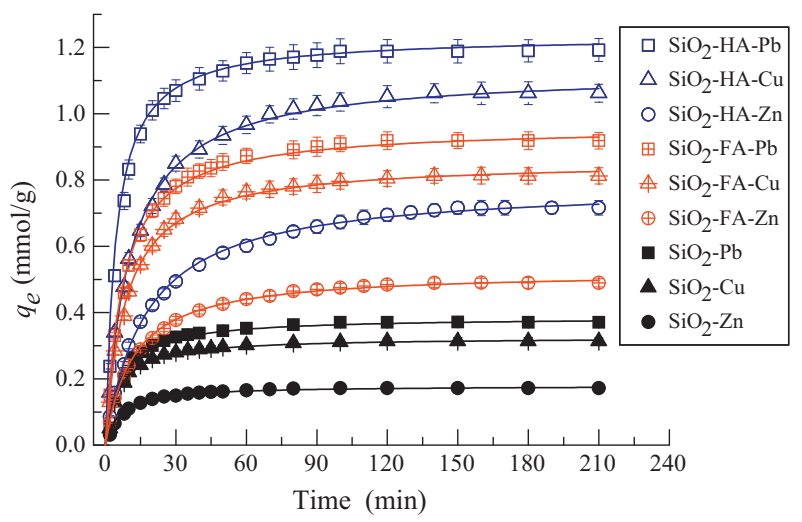

Fig. 1. Adsorption kinetics of the metal cations on $\mathrm{SiO}_{2}, \mathrm{SiO}_{2}-\mathrm{FA}$ and $\mathrm{SiO}_{2}-\mathrm{HA}$ nanoparticles (dots), and pseudo-second-order model (real lines) fittings.

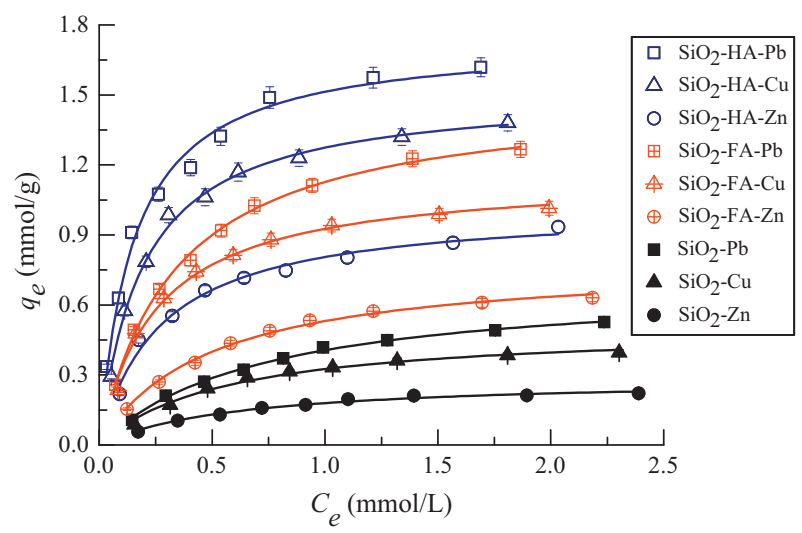

Fig. 2. Adsorption isotherms of the metal cations on $\mathrm{SiO}_{2}, \mathrm{SiO}_{2}-\mathrm{FA}$ and $\mathrm{SiO}_{2}-\mathrm{HA}$ nanoparticles at pH 5.0 (dots), and Langmuir model (real lines) fittings.

was approached for all the metal cations on the nanoparticles and thus the equilibrium time of $180 \mathrm{~min}$ was adopted in the following adsorption experiments. Both the adsorbed amount $\left(q_{e}\right)$ and the initial adsorption rate $\left(v_{0}\right)$ followed the sequence: $\mathrm{Pb}(\mathrm{II})>\mathrm{Cu}(\mathrm{II})>\mathrm{Zn}(\mathrm{II})$, irrespective of coating with FA or HA. It is noticeable that the initial adsorption rates of the cations distinctly exhibited the following sequence: $\mathrm{SiO}_{2}-\mathrm{HA}>\mathrm{SiO}_{2}-\mathrm{FA}>$ the original $\mathrm{SiO}_{2}$ (Fig. 1), indicative of a stronger affinity of the coated nanoparticles for the cations than the original $\mathrm{SiO}_{2}$ particles.

Adsorption isotherms of the cations on the nanoparticles are displayed in Fig. 2, together with the fittings of the Langmuir model. The equilibrium data fit well with the model and the relevant parameters are listed in Table 2. Similar to the adsorption kinetic results, the adsorption capacities $\left(q_{\max }\right)$ exhibited the following sequence: $\mathrm{Pb}(\mathrm{II})>\mathrm{Cu}(\mathrm{II})>\mathrm{Zn}(\mathrm{II})$, and the FA/HA coated nanoparticles, particularly the $\mathrm{SiO}_{2}-\mathrm{HA}$, exhibited higher adsorption capacities for the cations than the original $\mathrm{SiO}_{2}$ nanoparticles.

Table 2

Langmuir parameters for metal cation adsorption on $\mathrm{SiO}_{2}, \mathrm{SiO}_{2}$-humic acid and $\mathrm{SiO}_{2}$-fulvic acid nanoparticles at pH 5.0.

\begin{tabular}{lllll}
\hline Adsorbent & Cation & $q_{\max }(\mathrm{mmol} / \mathrm{g})$ & $K_{L}(\mathrm{~L} / \mathrm{mmol})$ & $R^{2}$ \\
\hline $\mathrm{SiO}_{2}$ & $\mathrm{~Pb}$ & 0.699 & 1.387 & 0.997 \\
& $\mathrm{Cu}$ & 0.507 & 1.788 & 0.985 \\
& $\mathrm{Zn}$ & 0.288 & 1.657 & 0.983 \\
$\mathrm{SiO}_{2}-\mathrm{HA}$ & $\mathrm{Pb}$ & 1.744 & 6.591 & 0.990 \\
& $\mathrm{Cu}$ & 1.516 & 5.272 & 0.995 \\
& $\mathrm{Zn}$ & 1.023 & 3.705 & 0.985 \\
$\mathrm{SiO}_{2}-\mathrm{FA}$ & $\mathrm{Pb}$ & 1.508 & 2.964 & 0.998 \\
& $\mathrm{Cu}$ & 1.158 & 4.012 & 0.993 \\
& $\mathrm{Zn}$ & 0.791 & 2.046 & 0.995 \\
\hline
\end{tabular}




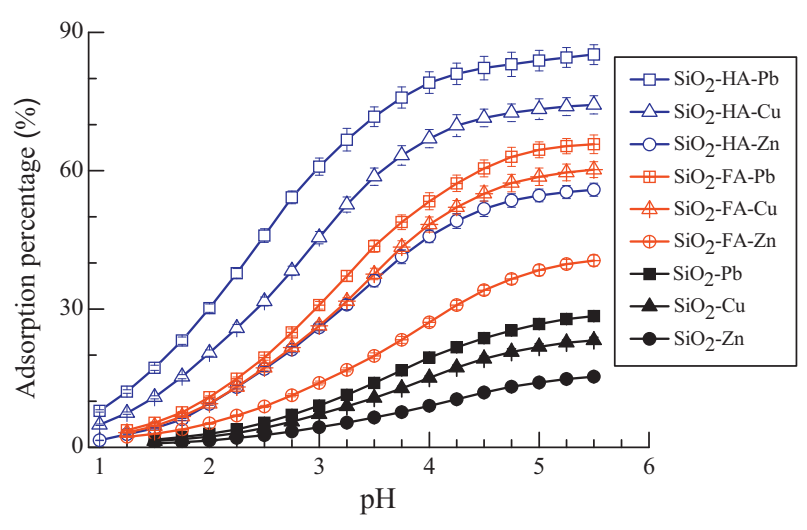

Fig. 3. Effect of $\mathrm{pH}$ on the metal cation adsorption on $\mathrm{SiO}_{2}, \mathrm{SiO}_{2}-\mathrm{FA}$ and $\mathrm{SiO}_{2}-\mathrm{HA}$ nanoparticles at $0.01 \mathrm{~mol} / \mathrm{L} \mathrm{NaNO}_{3}$.

\subsection{Effects of $p H$ and ionic strength}

The cation adsorption was strongly $\mathrm{pH}$-dependent as shown in Fig. 3. Metal cation adsorption increased in a narrow $\mathrm{pH}$ range (2-3 $\mathrm{pH}$ units). This critical interval, known as the adsorption edge, is graphically represented in the adsorption envelopes [18]. Adsorption of FA/HA onto the surface of clay minerals decreased under high $\mathrm{pH}$ conditions, favoring the dissolution of $\mathrm{HA}$ and desorption of FA $[19,20]$. Nevertheless, it is interesting to note that cation adsorption on $\mathrm{SiO}_{2}-\mathrm{FA}$ and $\mathrm{SiO}_{2}-\mathrm{HA}$ followed the same $\mathrm{pH}$-dependent trend as that for the original $\mathrm{SiO}_{2}$ particles, and $\mathrm{FA} / \mathrm{HA}$ coated nanoparticles always exhibited a higher affinity for the cations than did the original nanoparticles.

It is also noticeable that ionic strength had no remarkable effect on the cation adsorption. Here the effect of ionic strength on $\mathrm{Cu}$ (II) adsorption was present as an example (Fig. 4) due to the high similarity of the results obtained for different cations. Effect of ionic strength is often linked to distinguishing inner-sphere adsorption from outer-sphere adsorption [21,22]. Therefore, the absence of ionic strength effect in this experiment might suggest that the cations primarily formed inner-sphere complexes with the nanoparticles. However, this information needs to be disambiguated by direct evidence.

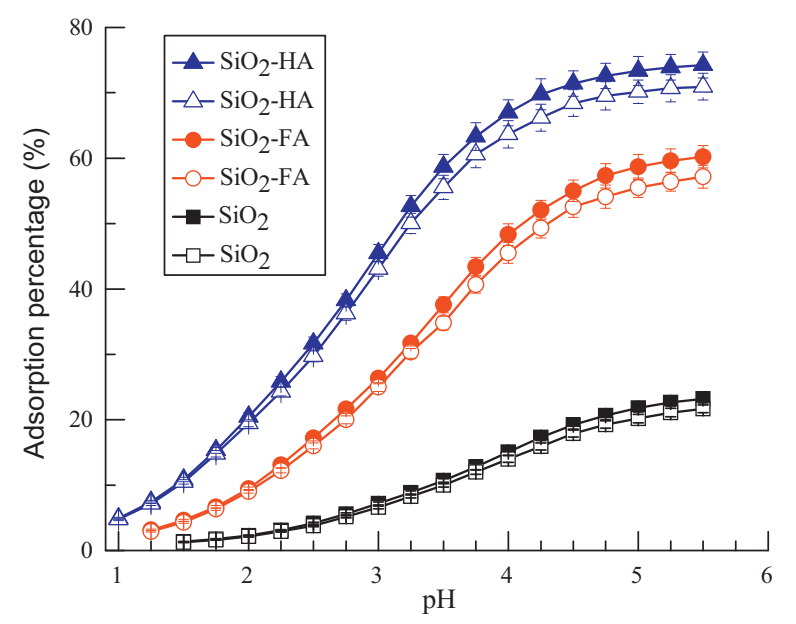

Fig. 4. Effect of ionic strength on $\mathrm{Cu}(\mathrm{II})$ adsorption on $\mathrm{SiO}_{2}, \mathrm{SiO}_{2}-\mathrm{FA}$ and $\mathrm{SiO}_{2}-\mathrm{HA}$ nanoparticles. Solid and open symbols indicate 0.01 and $0.1 \mathrm{~mol} / \mathrm{L} \mathrm{NaNO}_{3}$, respectively.

\subsection{X-ray absorption spectroscopy analysis}

In order to distinguish the differences in coordination environment of metal cations between $\mathrm{SiO}_{2}$ and $\mathrm{FA} / \mathrm{HA}$ coated $\mathrm{SiO}_{2}$, XAS analysis was performed on the adsorption samples. Due to the practical limitation, XAS study was only performed for $\mathrm{Cu}(\mathrm{II})$. The normalized K-edge XANES spectra and their first derivatives for the reference compounds and the $\mathrm{Cu}(\mathrm{II})$ adsorption samples are shown in Fig. 5a and b, respectively. Previous results have indicated preedge peak is sensitive to the presence of a center of symmetry, and its intensity increases with distortions that remove this center of symmetry [23]. The first derivatives of the XANES spectra (Fig. 5b) showed an obvious splitting of peaks of $\alpha$ and $\beta$, which could be attributed to the tetragonal distortion of the $\mathrm{Cu}-\mathrm{O}$ octahedron caused by the Jahn-Teller effect [24]. Compared with $\mathrm{Cu}^{2+}$ (aqueous), the $\mathrm{Cu}$ (II) adsorbed were gradually diminished in the $\alpha$ peak intensity (Fig. 5b), indicating octahedral $\mathrm{Cu}$ binding sites in the adsorption samples were tetragonally distorted by the complexation with ligands (e.g. hydroxy or organic) in the nanoparticle surfaces.

The $k^{3}$-weighted EXAFS spectra of $\mathrm{Cu}(\mathrm{II})$ adsorbed and the corresponding radial structure functions derived from Fourier transformations are presented in Fig. $5 c$ and $d$, respectively. The first coordination shell was composed of four $\mathrm{O}$ atoms at a distance of 1.94-1.97 $\AA$ in all the adsorption samples (Table 3). These four atoms were most likely positioned in the equatorial plane of a Jahn-Teller distorted octahedron, while the axial $\mathrm{O}$ atoms were difficult to be detected because contributions from the more distant axial $O$ atoms to the EXAFS signals were too small. In all the adsorption samples, a second coordination shell neighbor at 2.91-3.31 was found which could be attributed to the interaction between $\mathrm{Si} / \mathrm{O} / \mathrm{C}$ and $\mathrm{Cu}[25]$. For $\mathrm{Cu}(\mathrm{II})$ adsorbed on the FA/HA coated $\mathrm{SiO}_{2}$, the interatomic distance ranged 2.91-3.02 $\AA$; while distance was much longer $(3.31 \AA$ ) for the original nanoparticles. This indicates that, being different from the original nanoparticles, a similar coordination environment exists for $\mathrm{Cu}$ (II) adsorption on FA/HA coated $\mathrm{SiO}_{2}$. Since the interatomic distance was larger for $\mathrm{Cu}(\mathrm{II})$ adsorbed on the original $\mathrm{SiO}_{2}$ than the $\mathrm{FA} / \mathrm{HA}$ coated $\mathrm{SiO}_{2}$, a heavier atom was expected to be in the second shell of $\mathrm{SiO}_{2}-\mathrm{Cu}$ compared with $\mathrm{SiO}_{2}-\mathrm{FA}-\mathrm{Cu}$ or $\mathrm{SiO}_{2}-\mathrm{HA}-\mathrm{Cu}$. The best fitting results from the radial distribution functions of the spectra (Fig. 5d) were obtained when $\mathrm{C}$ was used in the second shell of $\mathrm{SiO}_{2}-\mathrm{FA}-\mathrm{Cu}$ and $\mathrm{SiO}_{2}-\mathrm{HA}-\mathrm{Cu}$, while it was true when $\mathrm{Si}$ was used as the second shell neighbor of $\mathrm{SiO}_{2}-\mathrm{Cu}$. EXAFS spectra fitting (Table 3) showed that about $2 \mathrm{Si}$ atoms connected to the center atom of $\mathrm{Cu}$ at a distance of $3.31 \AA$ for the adsorption samples of the original $\mathrm{SiO}_{2}$, suggesting an edge-sharing structure between $\mathrm{SiO}_{2}$ octahedron and tetragonal of $\mathrm{Cu}-\mathrm{O}$. Whereas, the fitting data of $1.2-2.6 \mathrm{C}$ atoms at a distance of 2.91-3.01 А̊ were evidenced for the adsorption samples of $\mathrm{SiO}_{2}-\mathrm{FA}$ and $\mathrm{SiO}_{2}-\mathrm{HA}$, which are consistent with the earlier research for $\mathrm{Cu}$ adsorption in the presence of natural organic matter [9]. The XAS analysis provided direct evidence for the formation of inner-sphere complexes of the cations adsorbed on $\mathrm{SiO}_{2}$; whereas cations were primarily bonded to the carbonic functional groups of FA/HA on the coated nanoparticles.

\section{Discussion}

Our previous work has demonstrated that $\mathrm{SiO}_{2}$ nanoparticles have a strong affinity for FA and HA, and FTIR spectra also revealed that the nanoparticles entailed a large number of carboxyl and aromatic moieties after being coated with the FA and HA [13]. As indicated by the present study, nano- $\mathrm{SiO}_{2}$ had an obvious adsorption affinity for $\mathrm{Cu}(\mathrm{II}), \mathrm{Zn}$ (II) and $\mathrm{Pb}(\mathrm{II})$ cations (Figs. 1 and 2) probably through ligand exchange. The $\zeta$ potential analysis showed 

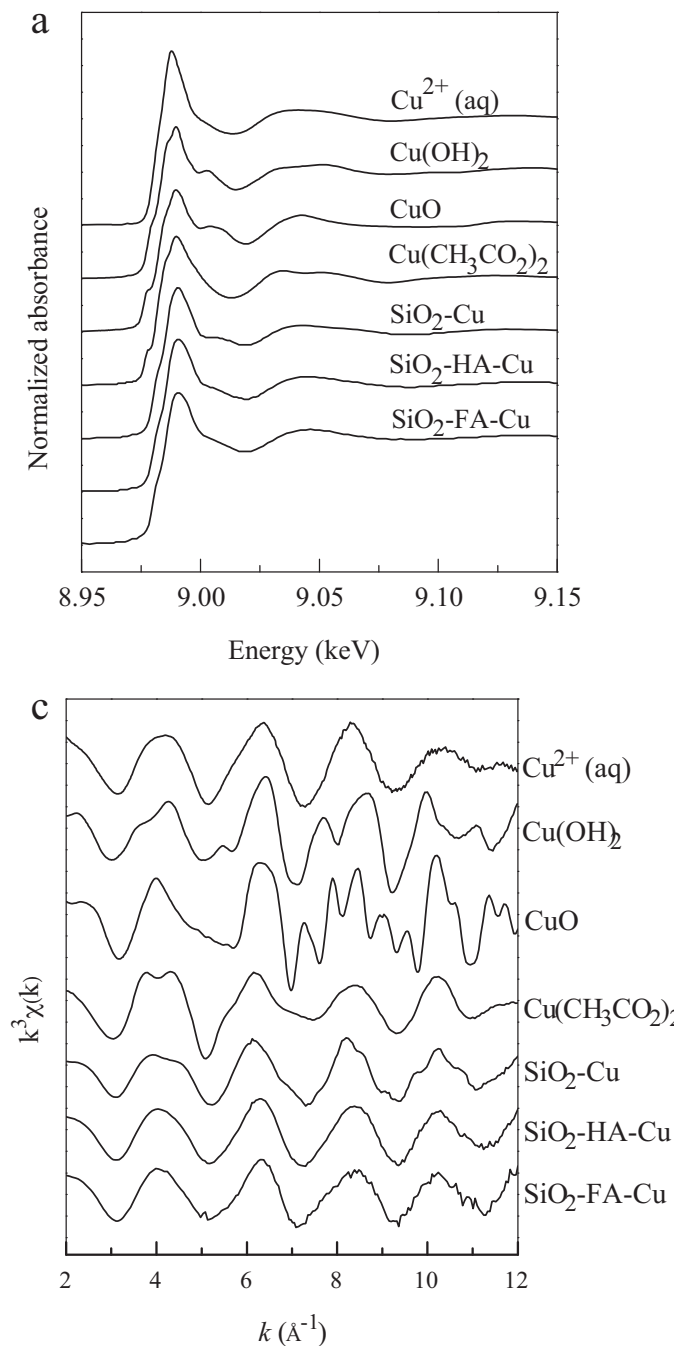

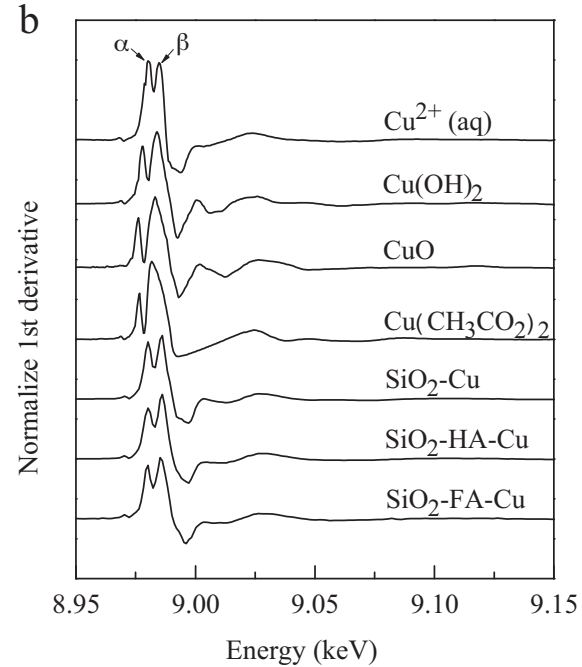

d

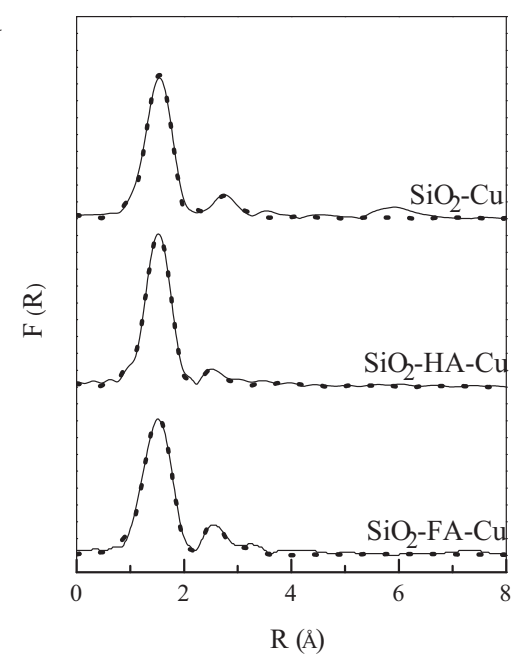

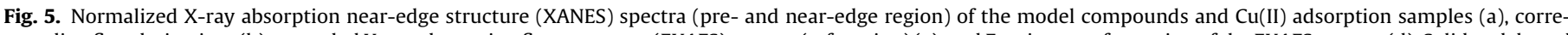

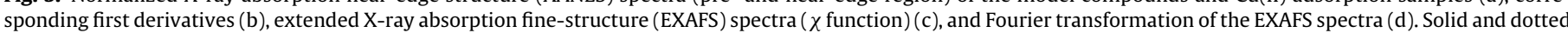

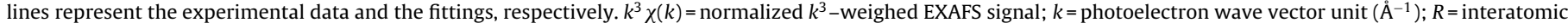
distance $(\AA)$.

that nano- $\mathrm{SiO}_{2}$ had a low IEP of about 2.2 (Fig. 6), indicative of its possession of a lot of negative hydroxyl moieties [26]. After cation adsorption, the nanoparticle surface tended to charge positively and exhibited higher IEP (Fig. 6). It was therefore presumed that the cations can be chemisorbed instead of electrostatic attracted by the nanoparticles. In addition, the evidences of the good fittings of the adsorption kinetic data to the pseudo-second-order model and free ionic strength effect to the adsorption also suggested that the adsorption was a chemisorption process [16]. More impor- tantly, the XAS analysis unambiguously confirmed that $\mathrm{Cu}(\mathrm{II})$ cation formed inner-sphere surface complexes on nano- $\mathrm{SiO}_{2}$ particles.

Coating with FA and $\mathrm{HA}$ can provide $\mathrm{SiO}_{2}$ nanoparticles additional sorption sites for the cations by complexing them through the organic functional groups. It is known that HA possesses more complexing functional groups (e.g., carboxyl, aromatic and phenolate moieties) than FA. Consequently, HA can bind more strongly with both $\mathrm{SiO}_{2}$ nanoparticles and the metal cations, and thus $\mathrm{SiO}_{2}-\mathrm{HA}$ exhibited a higher adsorption capacity for the cations than did

Table 3

Structural parameters of the adsorption samples obtained from EXAFS spectra fitting.

\begin{tabular}{|c|c|c|c|c|c|c|c|c|c|}
\hline \multirow[t]{2}{*}{ Sample } & \multicolumn{4}{|c|}{ First shell } & \multicolumn{5}{|c|}{ Second shell } \\
\hline & $N^{\mathrm{a}}$ & $R^{\mathrm{b}}(\AA)$ & $\left(\sigma^{2}\right)^{\mathrm{c}}\left(\AA^{2}\right)$ & $\Delta E_{0}^{\mathrm{d}}(\mathrm{eV})$ & $N$ & $R(\AA)$ & $\sigma^{2}\left(\AA^{2}\right)$ & $\Delta E_{0}(\mathrm{eV})$ & $\%$ of fit ${ }^{\mathrm{e}}$ \\
\hline $\mathrm{SiO}_{2}-\mathrm{Cu}$ & 3.9 & 1.97 & 0.005 & 2.38 & 2.1 & 3.31 & 0.010 & 4.24 & 14.4 \\
\hline $\mathrm{SiO}_{2}-\mathrm{HA}-\mathrm{Cu}$ & 4.4 & 1.94 & 0.006 & 5.09 & 1.2 & 2.91 & 0.001 & 2.85 & 10.0 \\
\hline $\mathrm{SiO}_{2}-\mathrm{FA}-\mathrm{Cu}$ & 4.2 & 1.95 & 0.006 & 6.46 & 2.6 & 3.02 & 0.005 & 3.15 & 19.9 \\
\hline
\end{tabular}

a Coordination number.

b Interatomic distance.

c Debye-Waller disorder parameter.

d Energy shift.

e Percent contribution to the fit of the EXAFS spectra for each scattering path. 


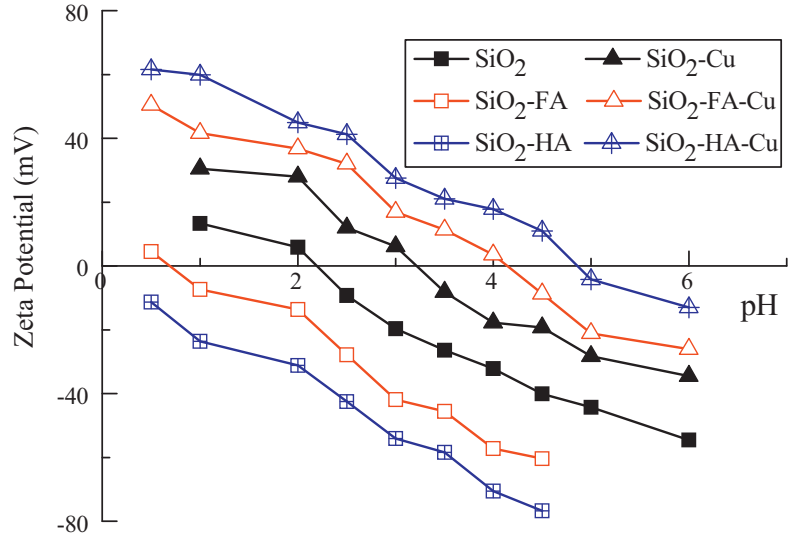

Fig. 6. Zeta potentials of $\mathrm{Cu}(\mathrm{II})$ adsorption on $\mathrm{SiO}_{2}, \mathrm{SiO}_{2}-\mathrm{FA}$ and $\mathrm{SiO}_{2}-\mathrm{HA}$ nanoparticles.

$\mathrm{SiO}_{2}$-FA. Although the specific surface areas of the coated nanoparticles were significantly decreased, which was believed to be closely related to the sorption capacity of nanoparticles [13], the effects of organic functional groups coated on the nanoparticle surfaces were more overwhelming for cation adsorption than the former influence factor.

Due to the nanometer effect, FA and HA have strong interactions with nano- $\mathrm{SiO}_{2}$ particles and therefore the coated nanoparticles are rather stable. As a consequence, we found an interesting phenomenon that the facilitating effects of FA and HA on cation adsorption on the nanoparticles were almost free from the influence of $\mathrm{pH}$ value in the tested range. Our previous experiments indicated that increased ionic strength could compress and reduce the mutual repulsions between HA and nanoparticles and thus facilitated HA adsorption, while no ionic strength effect was observed for small rigid molecules of FA [13]. Nevertheless, It is noteworthy that the present work showed the adsorption of the cations on both FA and HA coated nanoparticles was unaffected by ionic strength. Therefore, it can be presumed that the cations were adsorbed through complexing with hydroxyl moieties and organic functional groups on the nanoparticles depending on the types of moieties on the surfaces and formed the relatively stable inner-sphere complexes [27], which was confirmed by the XAS analysis by taking $\mathrm{Cu}$ as an example.

\section{Conclusions}

The results of this study demonstrated that nano- $\mathrm{SiO}_{2}$ particles had a high adsorption affinity for the metal cations of $\mathrm{Cu}$ (II), $\mathrm{Pb}$ (II) and $\mathrm{Zn}$ (II). Coating with FA/HA obviously promoted the adsorption of the metal cations on nano- $\mathrm{SiO}_{2}$ particles, which was more significant for HA coating. The adsorption of the metal cations on the original nano- $\mathrm{SiO}_{2}$ particles was strongly dependent on the $\mathrm{pH}$ of the equilibrium solution but independent of solution ionic strength, suggesting inner-sphere complexation as the adsorption mechanism for the metal cations. FA/HA coated nano- $\mathrm{SiO}_{2}$ followed the same $\mathrm{pH}$-dependent trend for metal cation adsorption and always exhibited a higher affinity for the cations than did the original nanoparticles. The XAS analysis for $\mathrm{Cu}$ adsorption samples provided further evidence for the formation of inner-sphere complexes and indicated that different from the direct bonding of $\mathrm{Cu}$ to $\mathrm{SiO}_{2}$ on the original nanoparticles, $\mathrm{Cu}$ was adsorbed on FA/HA coated $\mathrm{SiO}_{2}$ through complexing with the hydroxyl moieties and organic functional groups of FA/HA as bridges.

\section{Acknowledgements}

This work was funded by the National Basic Research Program of China (Project 2011CB936001) and the National Natural Science Foundation of China (grant no. 20921063, 20877083 and 20890110).

\section{References}

[1] A. Nel, T. Xia, L. Madler, N. Li, Toxic potential of materials at the nanolevel, Science 311 (2006) 622-627.

[2] M.R. Wiesner, G.V. Lowry, P. Alvarez, D. Dionysiou, P. Biswas, Assessing the risks of manufactured nanomaterials, Environ. Sci. Technol. 40 (2006) 4336-4345.

[3] K. Tiede, M. Hassellov, E. Breitbarth, Q. Chaudhry, A.B.A. Boxall, Considerations for environmental fate and ecotoxicity testing to support environmental risk assessments for engineered nanoparticles, J. Chromatogr. A 1216 (2009) 503-509.

[4] R.J. Aitken, M.Q. Chaudhry, A.B.A. Boxall, M. Hull, Manufacture and use of nanomaterials: current status in the UK and global trends, Occup. Med. 56 (2006) 300-306.

[5] S.B. Chen, Y.B. Ma, L. Chen, K. Xian, Adsorption of aqueous $\mathrm{Cd}^{2+}, \mathrm{Pb}^{2+}, \mathrm{Cu}^{2+}$ ions by nano-hydroxyapatite: single- and multi-metal competitive adsorption study, Geochem. J. 44 (2010) 233-239.

[6] S.L. Wan, X. Zhao, L. Lv, O. Su, H.N. Gu, B.C. Pan, W.M. Zhang, Z.W. Lin, J.F. Luan, Selective adsorption of $\mathrm{Cd}(\mathrm{II})$ and $\mathrm{Zn}$ (II) ions by nano-hydrous manganese dioxide (HMO)-encapsulated cation exchanger, Ind. Eng. Chem. Res. 49 (2010) 7574-7579.

[7] R. Kretzschmar, H. Holthoff, H. Sticher, Influence of $\mathrm{pH}$ and humic acid on coagulation kinetics of kaolinite: a dynamic light scattering study, J. Colloid Interface Sci. 202 (1998) 95-103.

[8] K.J. Wang, B.S. Xing, Structural and sorption characteristics of adsorbed humic acid on clay minerals, J. Environ. Qual. 34 (2005) 342-349.

[9] Y.J. Lee, E.J. Elzinga, R.J. Reeder, Cu(II) adsorption at the calcite-water interface in the presence of natural organic matter: kinetic studies and molecular-scale characterization, Geochim. Cosmochim. Acta 69 (2005) 49-61.

[10] I. Christl, R. Kretzschmar, Interaction of copper and fulvic acid at the hematite-water interface, Geochim. Cosmochim. Acta 65 (2001) 3435-3442.

[11] C.L. Chen, X.K. Wang, Sorption of Th(IV) to silica as a function of $\mathrm{pH}$, humic/fulvic acid, ionic strength, electrolyte type, Appl. Radiat. Isot. 65 (2007) 155-163.

[12] K. Yang, D.H. Lin, B.S. Xing, Interactions of humic acid with nanosized inorganic oxides, Langmuir 25 (2009) 3571-3576.

[13] L. Liang, L. Luo, S.Z. Zhang, Adsorption and desorption of humic and fulvic acids on $\mathrm{SiO}_{2}$ particles at nano- and micro-scales, Colloids Surf. A: Physicochem. Eng. Aspects 384 (2011) 126-130.

[14] R.S. Swift, Organic matter characterization, in: D.L. Sparks, A.L. Page, P.A Helmke, R.H. Loeppert, P.N. Soltanpour, M.A. Tabatabai, C.T.Johnston, M.E.Sumner (Eds.), Methods of Soil Analysis, Part 3, Chemical Methods, Soil Science Society of America Inc., Madison, WI, 1996, pp. 1018-1024.

[15] Y.S. Ho, G. McKay, A comparison of chemisorption kinetic models applied to pollutant removal on various sorbents, Process Saf. Environ. Prot. 76 (1998) 332-340.

[16] Y.S. Ho, G. McKay, The kinetics of sorption of divalent metal ions onto sphagnum moss flat, Water Res. 34 (2000) 735-742.

[17] S.I. Zabinsky, J.J. Rehr, A. Ankudinov, R.C. Albers, M.J. Eller, Multiple-scattering calculations of X-ray-absorption spectra, Phys. Rev. B: Condens. Matter 52 (1995) 2995-3009.

[18] G. Sposito, The Chemistry of Soils, Oxford, New York, 1984, p. 277.

[19] G. Abate, J.C. Masini, Influence of $\mathrm{pH}$, ionic strength and humic acid on adsorption of $\mathrm{Cd}(\mathrm{II})$ and $\mathrm{Pb}(\mathrm{II})$ onto vermiculite, Colloids Surf. A: Physicochem. Eng. Aspects 262 (2005) 33-39.

[20] M. Arias, M.T. Barral, J.C. Mejuto, Enhancement of copper and cadmium adsorption on kaolin by the presence of humic acids, Chemosphere 48 (2002) 1081-1088.

[21] D.L. Sparks, Environmental Soil Chemistry, Academic Press, San Diego, CA, 1995

[22] S. Goldberg, L.J. Criscenti, D.R. Turner, J.A. Davis, K.J. Cantrell, Adsorption-desorption processes in subsurface reactive transport modeling Vadose Zone J. 6 (2007) 407-435

[23] X.Y. Guo, S.Z. Zhang, X.Q. Shan, L. Luo, Z.G. Pei, Y.G. Zhu, T. Liu, Y.N. Xie, A. Gault, Characterization of $\mathrm{Pb}, \mathrm{Cu}$, and $\mathrm{Cd}$ adsorption on particulate organic matter in soil, Environ. Toxicol. Chem. 25 (2006) 2366-2373.

[24] K. Xia, W. Bleam, P.A. Helmke, Studies of the nature of $\mathrm{Cu}^{2+}$ and $\mathrm{Pb}^{2+}$ binding sites in soil humic substances using X-ray absorption spectroscopy, Geochim. Cosmochim. Acta 61 (1997) 2211-2221.

[25] T. Karlsson, P. Persson, U. Skyllberg, Complexation of copper(II) in organic soils and in dissolved organic matter-EXAFS evidence for chelate ring structures, Environ. Sci. Technol. 40 (2006) 2623-2628.

[26] H.L. Tang, H.G. Xiong, S.W. Tang, P. Zou, A starch-based biodegradable film modified by nano silicon dioxide, J. Appl. Polym. Sci. 113 (2009) 34-40.

[27] Y. Li, Q.Y. Yue, B.Y. Gao, Adsorption kinetics and desorption of $\mathrm{Cu}(\mathrm{II})$ and $\mathrm{Zn}(\mathrm{II})$ from aqueous solution onto humic acid, J. Hazard. Mater. 178 (2010) 455-461. 